Royen, P. van, Rees, C.E., Groenewegen, P. Patient-centred interprofessional collaboration in primary care: challenges for clinical, educational and health services research. An EGPRN

\begin{tabular}{|l|l|}
$\begin{array}{l}\text { Postprint } \\
\text { Version }\end{array}$ & 1.0 \\
\hline Journal website & http://informahealthcare.com/doi/abs/10.3109/13814788.2014.908462 \\
\hline Pubmed link & $\underline{\text { http://www.ncbi.nlm.nih.gov/pubmed/?term=24882115 }}$ \\
\hline DOI & $10.3109 / 13814788.2014 .908462$ \\
\hline
\end{tabular}

This is a NIVEL certified Post Print, more info at http://www.nivel.eu

\title{
Patient-centred interprofessional collaboration in primary care: challenges for clinical, educational and health services research. An EGPRN keynote paper
}

\author{
Paul Van Royen ${ }^{1}$, Charlotte E Rees ${ }^{2}$, and Peter Groenewegen ${ }^{3,4}$ \\ ${ }^{1}$ Faculty of Medicine and Health Sciences, University of Antwerp, Belgium \\ ${ }^{2}$ Centre for Medical Education, University of Dundee, Scotland, UK \\ ${ }^{3}$ NIVEL-Netherlands Institute for Health Services Research, Utrecht, The Netherlands \\ ${ }^{4}$ Department of Sociology and Department of Human Geography, Utrecht University, Utrecht, \\ The Netherlands
}

\begin{abstract}
The theme 'patient-centred interprofessional collaboration' of the EGPRN conference in October 2012, captures in just three words important challenges for European primary care and its research agenda. Challenges for future research are formulated, in three domains: clinical, educational and health services research. Transferability of research, based upon advanced computational infrastructure, will facilitate a rapid learning health care system. In educational research, this includes the use of observational and reflexivity methods. Outcomes should be defined in terms of improvement of functional status and social participation rather than in terms of disease-specific outcomes. Partnership with all stakeholders, patients, GPs and their health care colleagues and students, can help in reducing avoidable waste in the production and reporting of research evidence.
\end{abstract}

\section{INTRODUCTION}

The theme of the EGPRN conference in Antwerp in October 2012 was 'Patientcentred interprofessional collaboration.' The subject of 'patient-centred interprofessional collaboration' captures in just three words important challenges for European primary care and its research agenda. 'Patient-centredness' relates to important epidemiological and societal changes. The epidemiological shift towards chronic disease and multi-morbidity challenges the current disease-oriented approach as the traditional basis for education, clinical practice and the organization of health 
Royen, P. van, Rees, C.E., Groenewegen, P. Patient-centred interprofessional collaboration in primary care: challenges for clinical, educational and health services research. An EGPRN keynote paper. European Journal of General Practice: 2014, 20(4), 327-332

care. There is also the societal challenge, with common transnational issues such as ageing, migration and cultural diversity, environmental and lifestyle hazards. Related to patient-centredness is 'professionalism' as in 'patient-centred professionalism,' which can be described as a set of attitudes, behaviours, practices, and relationships underpinning patient and public trust in doctors and the medical profession, achieved through patient-doctor partnerships based on respect, responsibility and accountability' (1).

'Interprofessional' relates to the challenges of designing an educational and occupational structure and an interprofessional health care workforce that can address the problems of future generations (2). With an ageing population, health problems change. Self-management becomes more important and an important role for health care professionals will be supporting people in adapting to their possibilities $(3,4)$. The same process of ageing populations requires innovations in health care organization to be able to care for an older population with fewer people.

Finally, 'collaboration' is necessary to facilitate the move from disease-oriented to patient-oriented care. However, patient-oriented care is not the endpoint of a development. The problems that people have do not always make them patients and at least not only patients. They are persons, with their own goals in life and they are embedded in a social and community context. Consequently, we should perhaps rather speak of the person- or community-centred organization of care. The implication is that person- and community-centred interprofessional collaboration will often be intersectoral collaboration at the intersection of primary and secondary care, public health and social care. Collaboration is influenced by funding and other incentives. Currently, the incentive structure is strongly influenced by the emphasis on market elements in health care organization. However, it has been observed that funding and incentive structures move towards population-based, prospective systems (5).

In this contribution, the three keynote speakers of the EGPRN conference in Antwerp formulate what they see as important challenges in the organization and performance of primary care-research with a clear link to the theme of the conference.

\section{CHALLENGES FOR CLINICAL RESEARCH}

\section{Real-world clinical practice data}

Facing the important societal and epidemiological changes and starting from the current landmarks in clinical research, as described in the European Research Agenda for General Practice/Family Medicine and Primary Health Care (6), there is a need for more research on primary care patients with multi-morbidity, acute and chronic diseases and polypharmacy at the same time. Trials are often performed on selected patients without co-morbidity, in contrast to real life, in which several drugs may be given concurrently. Therefore, many studies suffer from limited external validity (7). Increasingly, the value of new drugs is defined not just by clinical trial outcomes but also by what that drug actually does once it gets into an uncontrolled patient population. 
Royen, P. van, Rees, C.E., Groenewegen, P. Patient-centred interprofessional collaboration in primary care: challenges for clinical, educational and health services research. An EGPRN keynote paper. European Journal of General Practice: 2014, 20(4), 327-332

Therefore, there is a driving demand for real-world data, on patients with comorbidity taking multiple drugs in a flexible regimen and with a low to high adherence rate. How to get these? An open access is needed to vast stores of data on epidemiology, care pathways resource use and diagnoses. These real-life data can be obtained from cross-sectional and longitudinal databases containing mainly retrospective data, but also from patient registries, both large and small, including all patients treated at a particular primary care or specialized care centre. The single richest source of routine health care data lies within the records of Europe's general practitioners. Large observational and pragmatic interventional studies can be performed through interprofessional exchange and communication. We should foster, initiate and coordinate multinational and multiprofessional studies.

\section{Transferability of research facilitating a rapid learning health care system}

Patient-centeredness should also include research into the perspectives and attitudes of patients and physicians on how to set, rank and agree on treatment priorities or specific preferences for information, care, involvement and support, and to revise this ranking over time. Patient-centred and fully integrated research as part of primary health care provision demands a culture of observing and recording what is going on (data picturing usual care) and feedback on what is needed from practice to research (research questions). Feedback from results of observational and interventional research into practice creates shared ownership and transferability of the research process and results. To facilitate this, decision support systems, links to evidence and analysed overviews on own patient data and follow-up items will continue to develop and become more integrated with electronic patient record systems (8). Advanced computational infrastructure can improve integration of research questions and data retrieval for clinical research. Access to de-identified participant-level data from clinical research has many benefits, not only regarding external validity but there is also a positive correlation with research quality (9). An example of this 'learning health care system' concept is developed within the European project TRANSFoRm (http://www.transformproject.eu/) (10). ICT tools like those developed in this project will facilitate streamlined recruitment of patients into clinical trials as a matter of routine, without any bias, and whenever there is uncertainty about choice of treatment, which is frequent in primary care (8). For example, it is still not known which treatments are useful for acute stroke but if all patients in the world experiencing a stroke were admitted to trials, we would have enough patients within $24 \mathrm{~h}$ to decide on the most effective management of acute stroke. GPs have to realize that participating in RCTs may be in their patients' best interests, instead of perceiving a conflict between research and good patient care (11). There is also a challenge to fully include citizens and patients into research, not just as subjects or consumers, but as 'full' partners, i.e. taking part in defining the research problem, the analysis and interpretation of data, the action to improve or change the problem in so-called participatory action research. This partnership should be realized in cooperation with practice-based research networks, as a group of primary care practices devoted principally not only to primary care of patients, but also with a mission to investigate relevant questions related to community-based practice and to improve the quality of care (12). 
Royen, P. van, Rees, C.E., Groenewegen, P. Patient-centred interprofessional collaboration in primary care: challenges for clinical, educational and health services research. An EGPRN keynote paper. European Journal of General Practice: 2014, 20(4), 327-332

\section{Partnership in research}

There is a considerable, but avoidable waste in the production and reporting of research evidence, such as doing studies that are unnecessary or poorly designed, or the biased under-reporting of completed clinical research (13). Only the positive, sexy and exciting is published in the major journals, and studies with disappointing results are underreported, which results in substantial preventable suffering and death (9). Therefore, there is a call for an end to this unethical, unscientific and uneconomical practice.

Partnership in research can help in reducing this waste. Although, we have to overcome barriers in this field, such as lack of time and resources, full partnership has the potential to guide the research process-meaning that research is relevant to the end-users (patients and the public); recruitment is facilitated and allows for quick bidirectional translation of research questions and results (13). Patients and clinicians may prioritize other research outcomes such as human dignity, equity, solidarity, efficiency, transparency and self-determination. In particular, qualitative methodologies and action research have the potential to play a role in this partnership. Good examples can be found in the research on adherence to treatment (14). Partnership with patients would also mean that they are supported in moving away from passively waiting for an approach about an interesting research project towards being able to express an interest in participation as was shown in the SHARE project (15). Patients should also be seen as partners in the reporting of research evidence. Few journals have patients on their editorial boards or have patient advisory boards or patient editors.

\section{CHALLENGES FOR EDUCATIONAL RESEARCH}

\section{Patient-centred professionalism in the curriculum}

Patient-centred professionalism and interprofessional collaboration (PCPIC) are learnt as part of the formal (taught), informal (learnt) and hidden (organizational structures and cultures) curriculum (16). Students are taught PCPIC as part of university-based teaching $(17,18)$. However, they commonly witness lapses in PCPIC as part of their medical workplace learning, thereby creating dilemmas for students about how they should act. Should they behave in a manner consistent with university-sanctioned guidelines $(19,20)$, or should they instead adopt the behaviours of their clinical role models with whom they identify as members of the profession to which they want to belong? Students often feel unable to act in a manner consistent with the 'right' ethical course of action, despite knowing what those actions are, leading to moral distress (21).

\section{Research on medical professionalism education}

Research on medical professionalism education has blossomed over the last decade or so, with research questions clustering in four domains related to aspects of the formal, informal and hidden curriculum: (a) What is professionalism (formal, informal and hidden)? (b) How should professionalism be taught (formal)? (c) How 
Royen, P. van, Rees, C.E., Groenewegen, P. Patient-centred interprofessional collaboration in primary care: challenges for clinical, educational and health services research. An EGPRN keynote paper. European Journal of General Practice: 2014, 20(4), 327-332

is professionalism learnt (informal and hidden)? (d) How should professionalism be assessed (formal)? While diverse methods have been employed to address research questions in these four domains, it is common for research exploring professionalism teaching and assessment (the formal curriculum) to use quantitative methods (e.g. questionnaires and psychometric analyses of assessment instruments), and for research exploring what professionalism is and how it is learnt (informal and hidden curriculum) to use qualitative methods (e.g. discourse and thematic analyses of academic and grey literature, and students' talk and essays).

\section{Research on professionalism dilemmas of health care students}

To explore how students learn patient-centred professionalism and interprofessional collaboration in the medical workplace, an eight-year research programme was conducted exploring the professionalism dilemmas experienced by health care students. With four discrete but related studies across the UK and Australia with over 4000 health care students (from 66 individual and group interviews and two online surveys), we have collected over 2000 personal incident narratives of professionalism dilemmas (22-24). We found from our preliminary thematic framework analysis of all narratives that over $10 \%$ of professionalism dilemmas were interprofessional in nature (25). Common types of dilemmas experienced by medical students include them witnessing or participating in breaches of patient safety, patient dignity, and patient consent (including invalid consent for intimate examinations), students' inability to challenge others' professionalism lapses and students receiving abuse from clinical teachers and patients. All of these types of dilemmas are found in primary care, although few of the medical students' 'most memorable’ professionalism dilemmas take place in primary care (only 9.1\% of 680 written professionalism dilemmas collected via an online questionnaire) (23).

\section{Observational methods}

Although research has explored students' development of patient-centred professionalism using qualitative studies, few have employed observational methods, e.g. Stern (26). In a primary care context, we have explored the construction of power within the learning triad of GP tutor-patient-medical student using a video observation study. We found that power was enacted by GP tutors, students and patients using linguistic (e.g. questions), paralinguistic (e.g. laughter) and non-verbal communication (e.g. physical positioning). Although patients had more conversational input into the primary care bedside teaching encounters compared with hospital-based ones (27), GP tutors still employed disproportionately more questions, directives, and advice than students and patients, reflecting their enactment of power and higher institutional status. In this study at least, GP tutors did not always enact (and therefore, role model to the student) the espoused rhetoric of patient-centred professionalism.

\section{Educational and research implications}

Ultimately, GP educators can inadvertently create professionalism dilemmas for students by acting in a manner inconsistent with students' formal curriculum. They 
Royen, P. van, Rees, C.E., Groenewegen, P. Patient-centred interprofessional collaboration in primary care: challenges for clinical, educational and health services research. An EGPRN keynote paper. European Journal of General Practice: 2014, 20(4), 327-332

need to understand what PCPIC means within their own context and to discuss those understandings with students, and other health care colleagues. GP tutors can help students work with and through conflicts between the formal, informal and hidden curriculum through providing students with an open and safe forum to debrief, either on a one-to-one basis or through small groups. Not only should students be encouraged to share their dilemmas but GP tutors could model such sharing by discussing their own PCPIC dilemmas with students. Further research would benefit from innovative video reflexivity methods, whereby workplace interactions are video-recorded and then played back to participants to stimulate discussion. Such methods should help GP tutors and medical students to visualize PCPIC and potentially lead to further commitment to PCPIC (27).

\section{CHALLENGES FOR HEALTH SERVICES RESEARCH}

Patient-centred interprofessional collaboration in primary care can be studied at different levels from individual professionals and their patients to primary care practices and to health care systems (28). Health services research should study both the conditions that facilitate patient-centred collaboration, and its results in the daily practice of primary care.

\section{The level of professionals and their patients}

At the level of individual professionals and primary care practices, the internal organization of practices is important. There is a lack of knowledge on the required team skill mix to provide care that is tuned to the needs of individual patients and the local community (29). On the assumption that a range of skills embodied in different professions is involved, more knowledge is needed about the roles of different professionals in teams, especially the roles of relatively new professions, such as practice nursing, and the conditions for effective cooperation and division of tasks among them (30). Differences in social status positions and gender inequalities of professions are among these conditions.

\section{Organizational level}

At the level of organizations, effective interprofessional collaboration requires not only relationships between individual professionals but also that these relationships should be assured by (more formal) relationships between organizations. Patientcentred collaboration, especially regarding patients with complex health and social problems, requires a network of professionals with different skills and competences around a patient. However, such a network can only be assured if it is backed up by formal understandings or agreements between the home organizations of the different professionals involved.

\section{Health care system level}

At the macro level of health care systems, patient- centred interprofessional collaboration can be facilitated by improving human resource policies (31). From the point of view of interprofessional collaboration, human resource policies should focus on relationships and integration of traditionally separate areas: the educational 
Royen, P. van, Rees, C.E., Groenewegen, P. Patient-centred interprofessional collaboration in primary care: challenges for clinical, educational and health services research. An EGPRN keynote paper. European Journal of General Practice: 2014, 20(4), 327-332

and occupational system, different occupations, and different sectors of health and social care.

\section{Research challenges}

Patient-centred interprofessional collaboration in primary care should lead to beneficial outcomes for patients, and although it is generally assumed that the outcomes are positive, there is not much conclusive research. The main body of research that relates to this is in the areas of disease management and organizational models for chronic care. This research is relevant but does not focus explicitly on interprofessional collaboration. Disease management programmes are, by their nature, often not patient-centred but disease-centred. From a patient- or personcentred perspective, outcomes should be defined in terms of improvement of functional status and social participation rather than in terms of disease-specific outcomes (32).

There is a huge variation in how primary care is organized and how it relates to other sectors of health care-public health, hospital care, long-term care-and social care. Conditions for patient-centred collaboration, therefore, vary across Europe, providing opportunities for comparative research and identification of good practices (33). To use the European variation in primary care organization to explore the conditions for patient-centred collaboration, two strategies can be followed. The first strategy is to use information from as many health care systems as possible. With over 30 countries in the EU and the European Economic Area it is possible to use statistical analysis and in particular multilevel analysis, connecting health system characteristics to data on health care professionals and patients. The second strategy is to select a smaller number of countries on theoretical grounds, related to the assumed conditions for patient-centred care, in a comparative case study approach. For both strategies, cross-national research methodology has to be further developed.

\section{The link to policy}

We also need to know more about the transferability between countries of good practices, and organizational and service arrangements. What works under what health care system conditions? And finally, the results of this research have to find their way into policy and practice $(34,35)$. International comparative research poses extra challenges for researchers. Where it is relatively easy to identify relevant policy stakeholders in your own country, it is much more difficult to identify them in other countries and even more difficult on a European level. The EU does not have an official remit in health care policy, but is at the same time increasingly important through the linkage between economic policies, cost containment and reduction in health care, and the policy choices following from this. These policy processes are mostly blocked from the observation of researchers and policy makers in health care. Identifying the relevant stakeholders in other countries requires insight into the policy processes and access to networks in these countries. European nongovernmental organizations, such as the European Forum for Primary care, WoncaEurope and UEMO, can play an important role in translating research results from international comparative studies to the relevant stakeholders. 
Royen, P. van, Rees, C.E., Groenewegen, P. Patient-centred interprofessional collaboration in primary care: challenges for clinical, educational and health services research. An EGPRN keynote paper. European Journal of General Practice: 2014, 20(4), 327-332

\section{CONCLUSION}

In all three domains of research, both interprofessional collaboration and partnership with patients and health care professionals are important challenges for the future. There is a need for research at all levels (individual, interprofessional, local and national/international) involving multiple stakeholders, that means patients, GPs and their health care colleagues and students. Both qualitative and quantitative approaches are necessary, mostly in close relationship, resulting in multi-methods research and including methodological innovations. Well-designed international comparative research, focusing on the organization of care around patients at different levels, will facilitate learning health care systems. Finally, this research requires a team-based approach and should be translated back into policies and practice, so that all key stakeholders get involved in its implementation.

Declaration of interest: The authors report no conflicts of interest. The authors alone are responsible for the content and writing of the paper.

\section{REFERENCES}

Royal College of Physicians Doctors in Society. Medical Professionalism in a Changing World. London: Royal College of Physicians; 2005.

Frenk J, Chen L, Bhutta ZA, Cohen J, Crisp N, Evans T. et al. Health professionals for a new century: Transforming education to strengthen health systems in an interdependent world. Lancet 2010;376:1923-58.

Huber M, Knottnerus JA, Green L, van der Horst H, Jadad AR, Kromhout D, et al. How should we define health?Br Med J. 2011;343:d4163.

Ursum J, Rijken M, Heijmans M, Cardol M, Schellevis F. Care for chronically ill people: Organization of care, self-management and participation. Utrecht: NIVEL; 2011.

Charlesworth A, Davis A, Dixon J. Reforming payment for health care in Europe to achieve better value. London: Nuffield Trust; 2012.

Van Royen P, Beyer M, Chevallier P, Eilat-Tsanani S, Lionis C, Peremans L, et al. Series: The research agenda for general practice/family medicine and primary health care in Europe. Part 5: Needs and implications for future research and policy. Eur J Gen Pract. 2010;16:244-8.

Fortin M, Dionne J, Pinho G, Gignac J, Almirall J, Lapointe L. Randomized controlled trials: Do they have external validity for patients with multiple comorbidities?Ann Fam Med. 2006;4:104-8.

Weng, C, Appelbaum P, Hripcsak G, Kronish I, Busacca L, Davidson KW, et al. Using EHRs to integrate research with patient care: Promises and challenges. J Am Med Inform Assoc. 2012;19:684-7.

Chan AW, Song F, Vickers A, Jefferson T, Dickersin K, Gotzsche PC, et al. Increasing value and reducing waste: addressing inaccessible research. Lancet 2014;383:257-66.

TRANSFoRm. Translational medicine and patient safety in Europe. 2013. Available at http://www.transformproject.eu (accessed 30 December 2013).

Hummers-Pradier, E, Scheidt-Nave C, Martin H, Heinemann S, Kochen M, Himmel W. Simply no time? Barriers to GPs' participation in primary health care research. Fam Pract. 2008;25:105-12.

Tapp, H, Dulin M. The science of primary health-care improvement: Potential and use of community-based participatory research by practice-based research networks for translation of research into practice. Exp Biol Med (Maywood) 2010; 235:290-9.

Chalmers I, Bracken, MB Djulbegovic B, Garattini S, Grant J, Gulmezoglu AM, et al. How to increase value and reduce waste when research priorities are set. Lancet 2014;383:15665. 
Royen, P. van, Rees, C.E., Groenewegen, P. Patient-centred interprofessional collaboration in primary care: challenges for clinical, educational and health services research. An EGPRN keynote paper. European Journal of General Practice: 2014, 20(4), 327-332

Vermeire, E, Hearnshaw H, Rätsep A, Levasseur G, Petek D, van Dam H, et al. Obstacles to adherence in living with type 2 diabetes: An international qualitative study using metaethnography (EUROBSTACLE). Prim Care Diabetes 2007; 1:25-33.

Sullivan F, Treweek S, Grant A, Daly F, Nicolson D, McKinstry B, et al. Improving recruitment to clinical trials with a register of a million patients who agree to the use of their clinical records for research in the Scottish Health Research Register (SHARE). Trials 2011;12(Suppl 1)A115.

Hafferty FW. Beyond curriculum reform: Confronting medicine's hidden curriculum. Acad Med. 1998;73:403-7.

Thistlethwaite J. Interprofessional education: A review of context, learning and the research agenda. Med Educ. 2012;46:58-70.

Hean S, Craddock D, Hammick M. Theoretical insights into interprofessional education: AMEE Guide No. 62. Med Teacher 2012:34:e78-101.

General Medical Council. Good Medical Practice. London: GMC; 2013. Available at http://www.gmc-uk.org/static/documents/content/GMP_2013.pdf_51447599.pdf (accessed 30 December 2013).

World Federation for Medical Education/Association of Medical Schools in Europe International Task Force (2007) WFME Global Standards for Quality Improvement in Medical Education: European Specifications. Copenhagen, Denmark: WFME Office. Available at http://www.amse-med.eu/documents/EuropeanSpecifications.pdf (accessed 30 January 2014).

Jameton A. Nursing practice: The ethical issues. New York, NY: Prentice Hall; 1984.

Monrouxe LV, Rees CE. It's just a clash of cultures: Emotional talk within medical students' narratives of professionalism dilemmas. Adv Health Sci Educ. 2012;17:671-701.

Rees CE, Monrouxe LV, McDonald LA. Narrative, emotion, and action: Analysing 'most memorable' professionalism dilemmas. Med Educ. 2013;47:80-96.

Monrouxe LV, Rees CE, Endacott R, Ternan E. "Even now it makes me angry": healthcare students' professionalism dilemma narratives. Med Educ. 2014;48:502-17.

Rees CE, Monrouxe LV, Ajjawi R. Professionalism in workplace learning: Understanding interprofessional dilemmas through healthcare student narratives. In: Jindal-Snape D, Hannah E, editors. Exploring the dynamics of ethics in practice: Personal, professional and interprofessional dilemmas. Bristol: Policy Press; 2014. pp. 295-310.

Stern DT. In search of the informal curriculum: When and where professional values are taught. Acad Med. 1998;73:S28-30.

Rees CE, Ajjawi R, Monrouxe LV. The construction of power in family medicine bedside teaching encounters: A video-observation study. Med Educ. 2013;47:154-65.

Samuelson M, Tedeschi P, Aarendonk D, De la Cuesta C, Groenewegen PP. Improving interprofessional collaboration in primary care: position paper of the European Forum for Primary Care. Qual Prim Care 2012;20:303-12.

De Bakker D, Strassel J, Vrijhoef B, Derckx E. Support with education and employment of personnel: Skill mix analysis for general practices. Eerstelijns 2013,5:18-9.

Bourgeault IL, Kuhlmann E, Neiterman E, Wrede S. How can optimal skill mix be effectively implemented and why? HEN-OBS Joint Policy Brief No. 8. Copenhagen: World Health Organization; 2008.

Kuhlmann E, Batenburg R, Groenewegen PP, Larsen C. Bringing a European perspective to the health human resources debate: A scoping study. Health Policy 2013;110:6-13.

Rijken M, Bekkema N, Boeckxstaens P, Schellevis FG, De Maeseneer J, Groenewegen PP. Chronic disease management programmes: An adequate response to patients' needs? Health Expect 2012; doi: 10.111/j.1369-7625.2012.00786.x

Groenewegen PP. Analyzing European health systems: Europe as a research laboratory. Eur J Public Health 2013;23:185-6.

HSR Europe. Strengthening the European dimension of health services research. Policy Brief, June 2013. Available at http://www.healthservicesresearch.eu (accessed 30 December 2013).

Hansen J, Muscat NA, Keskimäki I, Lindahl AK, Pfaff H, Wismar M, et al. Measuring and improving the societal impact of health care research for European policy and practice. EuroHealth 2013; 19:32-5. 